\title{
Nasotracheal intubation \\ in the presence of frontobasal skull fracture
}

Joseph E. Arrowsmith MB BS MRCP(UK) FRCA, * Heidi J. Robertshaw MB BS, Juliet D. Boyd MB BS FRCA

Purpose: To present a case of maxillofacial trauma and basal skull fracture (BSF) in whom nasotracheal intubation (NTI) was successfully used, without complication, to facilitate surgical fixation. To present alternative methods of airway management in this situation and to review the evidence supporting the notion that NTI is contraindicated in the presence of basal skull fracture.

Clinical features: A 17-yr-old man was referred for surgical fixation of bilateral mandibular fractures. Cranial computed tomography revealed intracranial air and blood in all four sinuses and distortion of the nasal passage on the right. There was no cerebral injury and the left nasal passage appeared patent. In order to facilitate intraoperative intermaxillary fixation fibreoptic NTI was undertaken in preference to tracheostomy. The patient made an uneventful recovery without evidence of meningitis or direct cerebral injury.

Conclusion: In selected patients NTI may be performed in the presence of BSF. Available evidence suggests that BSF should not be regarded as an absolute contraindication to NTI.

Objectif : Présenter un cas de traumatisme maxillo-facial avec fracture de la base du crâne (FBS) chez qui une intubation nasotrachéale (INT) a été utilisée efficacement et sans complications pour une ostéosynthèse chirurgicale. Présenter des alternatives pour le contrôle des voies aériennes et revoir pourquoi on a toujours considéré I'INT comme contre-indiquée en présence d'une fracture de la base du crâne.

Éléments cliniques : Un homme de 17 ans a été référé pour ostéosynthèse chirurgicale de fractures mandibulaires bilatérales. La tomographie axiale révélait la présence d'air intracrânien et du sang dans les quatre sinus avec déformation des voies nasales du côté droit. II n'y avait pas de lésion cérébrale et les voies nasales gauches semblaient perméables. Dans le but de faciliter l'ostéosynthèse intermaxillaire, une INT par fibroscopie a été effectuée de préférence à une trachéotomie. Le patient a récupéré normalement sans évidence de méningite ni de blessure cérébrale directe.

Conclusion : Chez des patients choisis, I'INT demeure possible en présence de FBC. Les données disponibles suggèrent de ne pas considérer une FBC comme une contre-indication absolue à l'INT.

From the Department of Anaesthesia, St George's Healthcare NHS Trust, London SWl7 0QT, UK

"Current address: Department of Anesthesiology, Duke University Medical Center.

Address correspondence to: Dr. Joseph E. Arrowsmith, Department of Anesthesiology, Box 3094, Duke University Medical Center Erwin Road, Durham, NC 27710 USA.

Phone: +1 919681 3167; Fax: +1 919681 7901; E-mail: arrow002@mc.duke.edu

Presented at the summer meeting of the Southern Society of Anaesthetists, Epsom General Hospital, Surrey, UK, 1996.

Accepted for publication October 3, 1997. 
EVERE maxillofacial fractures may be associated with basal skull fracture (BSF) and frequently present with compromise of the upper airway. In patients with such injuries orotracheal intubation is often performed at the scene of injury or shortly after hospitalisation. Subsequent surgical reduction and fixation of mandibular and midface fractures may require realignment of dental occlusion and thus airway management without an orotracheal tube.

Current teaching suggests that nasotracheal intubation is contraindicated in the presence of systemic coagulopathy, intranasal abnormalities, nasal sinusitis, extensive facial fractures and BSF with or without leakage of cerebrospinal fluid (CSF). The anaesthetist is warned that nasotracheal intubation in the presence of BSF carries the risks of intracranial infection and direct cerebral injury. The view that nasotracheal intubation can be performed safely in such patients is still regarded as controversial and has stimulated much debate. ${ }^{1-5}$ In such cases the need to avoid nasotracheal intubation may lead to elective tracheostomy (a procedure itself not without risk) or orotracheal intubation and surgical fixation without the use of intraoperative intermaxillary fixation (IMF).

We describe the successful and uncomplicated use of fibreoptic nasotracheal intubation in the management of a patient with a BSF requiring anaesthesia for surgical fixation of mandibular fractures with IMF.

\section{Case report}

A previously well 17 -yr-old man was referred to this hospital for maxillofacial surgery following a road traffic accident. Depression of conscious level (Glasgow Coma Score: 7) and intermittent upper airway obstruction had necessitated orotracheal intubation and mechanical ventilation prior to transfer. The patient was admitted to the Intensive Care Unit (ICU) for a period of elective ventilation and observation before surgical fixation of the mandibular fractures. An acceptable level of sedation was achieved using infusions of propofol and morphine.

In addition to fractures of the right clavicle and both pubic rami on the left, plain radiographs revealed a minimally displaced fracture of the right zygoma and bilateral parasymphysial fractures of the mandible. The presence of mastoid ecchymosis (Battle's sign) indicated a clinical diagnosis of BSF. Cranial computed tomographs (CT) demonstrated intracranial air and fluid in the right frontal, ethmoid, sphenoid and maxillary sinuses. (Figure 1) There was no evidence of cerebral injury and the left nasal passage appeared patent. It was the opinion of the senior maxillofacial surgeon that reduc-

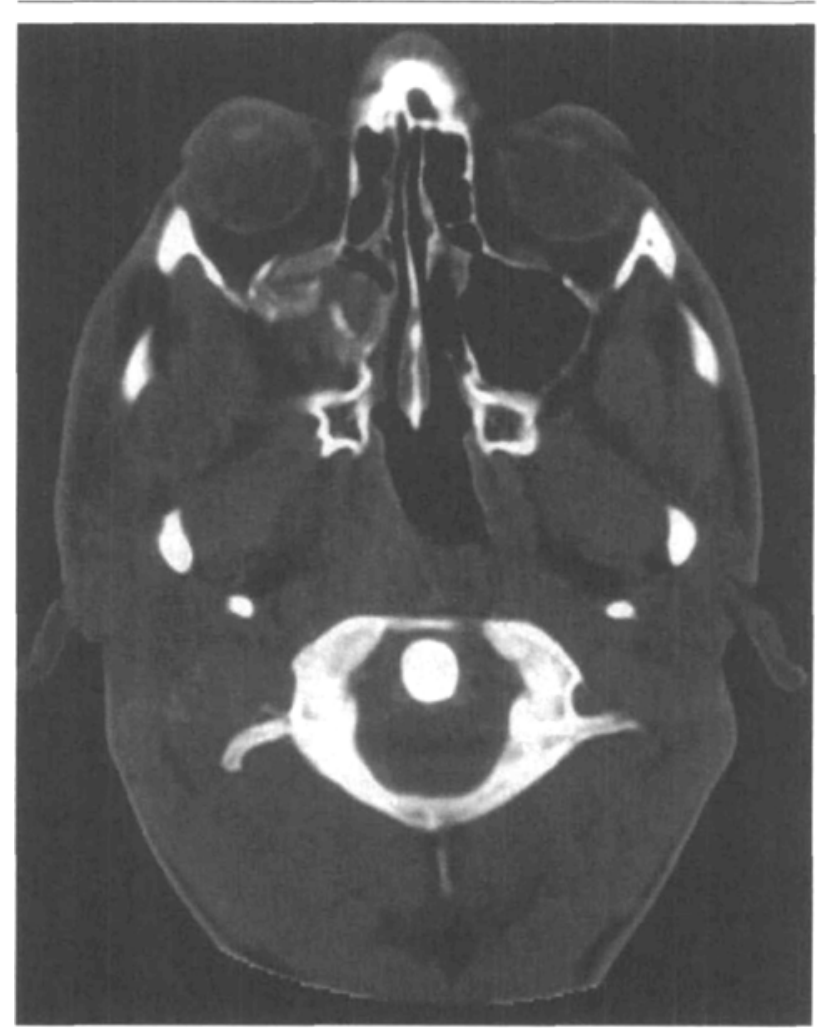

FIGURE 1 Cranial computed tomogram showing fluid in the right maxillary antrum and fractures of the posterior walls of the orbit and maxillary sinus. Further scans (not shown) additionally demonstrated the presence of intracranial air and fluid in the right frontal, sphenoid and etyhmoid sinuses.

tion and fixation of the mandibular fractures would require intraoperative IMF.

After prolonged discussion and further detailed scrutiny of the cranial CT scans it was decided to attempt fibreoptic nasotracheal intubation via the left nostril in preference to elective tracheostomy. In the event that nasotracheal intubation could not be performed the surgeon indicated that surgery would be performed without IMF in preference to tracheostomy. After transfer to the operating department anaesthesia was induced with isoflurane, $0.5-1.5 \%$, in oxygen and air, $\mathrm{F}_{\mathrm{I}} \mathrm{O}_{2}$ 0.4-1.0 and supplemented with incremental doses of fentanyl and vecuronium. Flucloxacillin $1 \mathrm{~g}$ and $1.2 \mathrm{~g}$ benzyl penicillin $i v$ were then administered. Following the instillation of $1 \mathrm{ml}$ phenylepherine $2.5 \%$, a flexible fibreoptic laryngoscope (Olympus LF-1, KeyMed) was passed without difficulty through the left nasal passage into the oropharynx. No obvious abnormality of the nasal passage was seen. A well lubricated, cuffed, $7.0 \mathrm{~mm}$ internal diameter endotracheal tube was then passed over the laryngoscope into the oropharynx 
without incident. Following a period of pre-oxygenation, the orotracheal tube was then removed, the nasal tube was advanced into the trachea under direct vision using Magill's forceps and an absorbent pack placed in the hypopharynx.

Following an uneventful three hour surgical procedure, the IMF wires and throat pack were removed and the patient returned to the ICU for further ventilation and observation. The nasotracheal tube was successfully removed eight hours later when spontaneous respiratory efforts were deemed adequate. The remainder of the patient's postoperative course was unremarkable. Specifically, there was neither CSF rhinorrhoea nor evidence of meningitis or direct cerebral injury.

\section{Discussion}

Radiographs demonstrating the inadvertent intracranial placement of nasogastric, ${ }^{6-8}$ nasopharyngeal ${ }^{9}$ and nasotracheal ${ }^{10}$ tubes are potent reminders of the hazards of blind instrumentation of the nasal passages in the presence of frontobasal fractures. Although most anaesthesia texts include basilar and facial fractures in the list of contraindications to nasotracheal intubation the evidence to support this recommendation is sparse and mainly based on anecdotal reports. ${ }^{11-15}$ The reports suggest that, in this clinical situation, the nasogastric tube is far more dangerous than the endotracheal tube. A Medline search using combinations of the MeSH terms "meningitis," "intubation, intratracheal," "cerebrospinal rhinorrhoea," "skull fractures" and "frontal bone" produced only two objective studies specifically addressing the issue. Both are retrospective.

In a study of 160 patients with BSF and CSF fistula, Bähr and Stoll reported that the route of tracheal intubation had no influence on the postoperative complication rate. ${ }^{16}$ There was no case of direct cerebral injury associated with nasotracheal intubation and the incidence of meningitis was the same, $2.5 \%$, after oral and nasal intubation. The authors concluded that nasal intubation was not contraindicated in the presence of fron- tobasal fractures. A commentary on the study, published in the same journal, admitted the limitations of the retrospective study design but stated that the authors had “... provided sufficient evidence to justify a prospective study."17 Unfortunately no details of the possible design of such a study were given.

In a study of 86 patients with clinical and/or radiological evidence of BSF, Rhee et al. set out to determine whether the complications of skull base fracture were increased by blind nasotracheal intubation performed in the field by experienced flight nurses. ${ }^{18}$ The complications were defined as; CSF leakage of $>24$ hr duration and/or meningitis, cranial nerve injury, diabetes insipidus and, intracranial placement of the endotracheal tube. Nasotracheal intubation was attempted in $38(44 \%)$ patients. There were no patients in whom the endotracheal tube was placed intracranially. Although the overall incidence of complications was high, $23 \%$, there was no difference between the two groups. (Table I) The authors concluded that attempts at blind nasotracheal intubation in the field did not markedly increase the complications associated with BSF.

In an attempt to avoid both tracheostomy and nasotracheal intubation in patients with BSF, the passage of an armoured endotracheal tube through the floor of the mouth has been advocated. Submental ${ }^{19,20}$ and both anterior and lateral submandibular routes ${ }^{21-23}$ have been described in the surgical management of severe panfacial fractures. The technique, in its various forms, is said to be relatively simple and safe to perform and produces a cosmetically acceptable scar. It is further claimed that it may be safely used for elective ventilation for periods of up to ten days. ${ }^{22}$

The use of an orotracheal tube does not, however, preclude temporary fixation of the mandible to the maxilla. In the management of a patient with both displaced nasal fractures and Le Fort III fractures, Farole and Piotrowski described the use of a novel splint to index the maxilla to the mandible permitting surgical fixation with IMF in the presence of an orotracheal tube. ${ }^{24} \mathrm{On}$

TABLE I Incidence of complications of basal skull fracture in patients in whom blind nasotracheal intubation (NTI) was attempted by experienced flight nurses compared to those in whom no attempt at NTI was made. CSF = cerebrospinal fluid. Adapted from Rhee $e t$ al. ${ }^{18}$ (reproduced with permission)

\begin{tabular}{|c|c|c|c|c|c|}
\hline & \multicolumn{2}{|c|}{$\begin{array}{l}\text { NTI attempted } \\
\quad(n=38)\end{array}$} & \multicolumn{2}{|c|}{$\begin{array}{c}\text { NTI not attempted } \\
\quad(n=48)\end{array}$} & \multirow[t]{2}{*}{$\begin{array}{c}P \\
\text { (Fisber's) }\end{array}$} \\
\hline & n (\%) & $95 \% \mathrm{CI}$ & n (\%) & $95 \% \mathrm{CI}$ & \\
\hline CSF leak and/or meningitis & $6(16)$ & $6-31 \%$ & $5(10)$ & $3-23 \%$ & 0.53 \\
\hline Cranial nerve injury & $2(5)$ & $1-18 \%$ & $8(17)$ & $7-30 \%$ & 0.17 \\
\hline Diabetes insipidus & $4(11)$ & $3-25 \%$ & $2(3)$ & $1-14 \%$ & 0.40 \\
\hline Any complication & $9(24)$ & $11-40 \%$ & $11(25)$ & $14-40 \%$ & 1.00 \\
\hline
\end{tabular}


one occasion one of us (JEA) has been able to route an orotracheal tube through the gap fortuitously left by missing incisors, thus permitting IMF.

The patient described above was, in our opinion, spared an unnecessary tracheostomy. We would not, however, advocate a complete disregard of current teaching and acknowledge that intraoperative dental occlusion often facilitates surgery but, whilst desirable, is by no means mandatory. Each patient and situation must be individually assessed and treated. ${ }^{2}$ The anaesthetist must be aware of the advantages, disadvantages and complications of the airway management strategies available. (Table II) Had the facial injuries in this patient been associated with worse tissue oedema, anatomical derangement and/or haemorrhage we would not have attempted nasotracheal intubation.

The advent of fibreoptic laryngoscopy has changed the options for management of patients with maxillofacial fractures. We suggest that it is time for a prospective, randomised trial comparing available airway management strategies in the treatment of patients with facial fractures and BSF requiring surgical fixation with intraoperative IMF. In making this suggestion we acknowledge that conducting such an investigation would present a number of problems. The current lack of prospective studies in this area could be interpreted as a measure of this.

Patients would have to be deemed suitable for application of each type of airway management strategy before randomisation. How best should patients failing to meet this entry criterion be managed? Obtaining informed consent may prove difficult in this group of patients. What should the endpoints be? The findings of retrospective studies indicate that the selection of study endpoints could have a major impact on the number of patients required to demonstrate any statistically significant differences in favour of any particular airway management strategy. Such endpoints might include; the incidence and severity of complications (of BSF, NTI, tracheostomy, submental intubation), patient outcome and satisfaction, surgeon satisfaction, duration of ICU and hospital stay and cost. It is our opinion that a large, international, multicentre study would be required.

\section{Acknowledgments}

We would like to thank Mr. Martin Danford and Dr. Susan Wright for their help and advice in the preparation of this manuscript.

TABLE II Comparison of the advantages, disadvantages and complications of tracheostomy and nasotracheal intubation in the perioperative management of patients with basal skull fracture.

\begin{tabular}{|c|c|c|}
\hline & Tracheostomy & Nasotracheal intubation \\
\hline \multirow[t]{3}{*}{ Pro } & Textbook approach & Avoids tracheostomy \\
\hline & Avoids risks of nasotracheal intubation & No surgical scar \\
\hline & May be used for prolonged intubation & \\
\hline \multirow[t]{14}{*}{ Con } & Requires additional surgery & "Contraindicated" \\
\hline & Surgical scar & $\begin{array}{l}\text { Unfeasible in the presence of distortion of nasal anatomy } \\
\text { or nasal packing }\end{array}$ \\
\hline & May delay primary surgical procedure & Requires fibreoptic laryngoscope and familiarity with use \\
\hline & May considerably delay securing airway in unintubated patient & Use of topical vasoconstrictor may be contraindicated \\
\hline & & $\begin{array}{l}\text { Unsuitable for prolonged intubation because of increased } \\
\text { resistance to breathing and difficulty in suctioning secretions }\end{array}$ \\
\hline & & Additional radiographic imaging may be required? \\
\hline & COMPLICATIONS & COMPLICATIONS \\
\hline & Haemorrhage - may be massive & Mucosal dissection \\
\hline & Local sepsis & Trauma to ademoids \\
\hline & Tracheomalacia & Haemorrhage - may be massive \\
\hline & Tracheal stenosis & Sinusitis \& Otitis \\
\hline & Pneumothorax & Bacteraemia \\
\hline & Laryngeal wall granuloma formation & Meningitis? \\
\hline & Mediastinitis? & Direct cerebral injury? \\
\hline
\end{tabular}




\section{References}

1 Hall $D B$. Nasotracheal intubation with facial fractures. JAMA 1989; 261: 1198.

2 Zmyslowski WP, Maloney PL. Nasotracheal intubation in the presence of facial fractures (Letter). JAMA 1989; 262: 1327-8.

3 Schultz RC. Nasotracheal intubation in the presence of facial fractures (Letter). Plast Reconstr Surg 1990; 86: 1046.

4 Bragg CL. Nasotracheal intubation versus tracheostomy in the presence of facial fractures (Letter). Plast Reconstr Surg 1991; 88: 740 .

5 Altermir FH. Nasotracheal intubation in patients with facial fractures (Letter). Plast Reconstr Surg 1992; 89: 165-6.

6 Seebacher J, Nozik $D$, Mathieu $A$. Inadvertent intracranial introduction of a nasogastric tube, a complication of severe maxillofacial trauma. Anesthesiology 1975; 42: $100-2$.

7 Bouzarth WF. Intracranial nasogastric tube insertion (Editorial). J Trauma 1978; 18: 818-9.

8 Fremstad JD, Martin SH. Lethal complication from insertion of nasogastric tube after severe basilar skull fracture. J Trauma 1978; 18: 820-1.

9 Muzzi DA, Losasso TJ, Cucchiara RF. Complication from a nasopharyngeal airway in a patient with a basilar skull fracture. Anesthesiology 1991; 74: 366-8.

10 Horellou MF, Mathe D, Feiss P. A hazard of nasotracheal intubation (Letter). Anaesthesia 1978; 33: 73-4.

11 Stebling LC. Management of the airway. In: Barash PG, Cullen BF, Stoelting RK (Eds.). Clinical Anesthesia, 2nd ed. Philadelphia: JB Lippincott Co., 1992: 685-708.

12 Stone DJ, Gal TJ. Airway management. In: Miller RD (Ed.). Anesthesia, 4th ed. New York: Churchill Livingstone, 1994: 1403-35.

13 Florete OG Jr. Airway management. In: Civetta JM, Taylor RW, Kirby RR (Eds.). Critical Care, 2nd ed. Philadelphia: JB Lippincott, 1992: 1419-36.

$14 O^{\prime}$ Connell $F$. Management of the airway and endotracheal intubation. In: Murray MJ, Coursin DB, Pearl RG, Prough DS (Eds.). Critical Care Medicine. Perioperative Management. Philadelphia: LippincottRaven, 1996: 57-70.

15 Gotta $A W$. Management of the traumatized airway. In: American Society of Anesthesiologists. Annual Refresher Course Lectures. Philadelphia: Lippincott, 1994: 226, 1-7.

16 Bäbr W, Stoll P. Nasal intubation in the presence of frontobasal fractures: a retrospective study. J Oral Maxillofac Surg 1992; 50: 445-7.
17 Keenan RL. Nasal intubation in the presence of frontobasal fractures: a retrospective study. J Oral Maxillofac Surg 1992; 50: 447-8.

18 Rhee KJ, Muntz CB, Donald PJ, Yamada JM. Does nasotracheal intubation increase complications in patients with skull base fractures? Ann Emerg Med 1993; 22: 1145-7.

19 Taber $A A Y$. Nasotracheal intubation in patients with facial fractures (Letter). Plastic Reconstr Surg 1992; 90: 1119-20.

20 Altemir $F H$. The submental route for endotracheal intubation. A new technique. Journal of Maxillofacial Surgery 1986; 14: 64-5.

21 Hönig JF, Braun U. Laterosubmental tracheal intubation. An alternative method to nasal-oral intubation or tracheostomy in single-step treatment of panfacial multiple fractures or osteotomies. (German) Anaesthesist 1993; 42: 256-8.

22 Stoll $P$, Galli $C$, Wächter $R$, Bäbr W. Submandibular endotracheal intubation in panfacial fractures (Letter). J Clin Anesth 1994; 6: 83-6.

23 Katsnelson $T$, Farcon E, Adamo AR. More on submandibular endotracheal intubation for panfacial fractures (Letter). J Clin Anesth 1994; 6: 527-8.

24 Farole $A$, Piotrowski JC. A unique indexing splint for use in combined Le Fort and nasal injuries to avoid tracheostomy. Oral Surg Oral Med Oral Pathol 1990; 70: $399-400$. 